\title{
O Rio Paraíba do Sul na IX Região Hidrográfica do Estado do Rio de Janeiro: impactos e possibilidades de uso.
}

\author{
Rafael Espinoza Gomes Roseira André1 \\ Gilcélio de Souza do Nascimento ${ }^{1}$ \\ José Augusto Ferreira Silva ${ }^{1}$
}
${ }^{1}$ Instituto Federal de Educação, Ciência e Tecnologia Fluminense - IFF Campus Campos/Centro Rua Dr. Siqueira, 273, Pq. Dom Bosco - 28030-130 - Campos dos Goytacazes/RJ, Brasil rafaelespinoza_andre@hotmail.com gil.sig2009@gmail.com jaferreirasilva@gmail.com

\begin{abstract}
This study proposes to discuss the deterioration on the fluminense passage of the River Paraiba do Sul, to evaluate its importance in the context of the IX Hydrographic Region of Rio de Janeiro State, as well the opportunities for its sustainable management. For this, the GIS (Geographic Information System) will form a database that will provide informations in a logical and structured way for management and decision-making process of the different spheres of application of Hydric Resources.
\end{abstract}

Palavras-chave: River Paraíba do Sul, Hydric resources management, GIS, Rio Paraíba do Sul, Gestão dos Recursos Hídricos, SIG.

\section{A importância da gestão dos recursos hídricos}

Sabe-se que a água é um recurso fundamental para a vida na Terra, pois propiciou o surgimento dos diferentes tipos de vida e sua manutenção. A má utilização deste recurso se torna um problema Regional, como é o caso da IX Região Hidrográfica, visto que a demanda da água atingiu as esferas urbana e rural, em suas atividades econômicas e em seu abastecimento humano, de forma acelerada.

O acelerado crescimento populacional, a falta de saneamento básico, a intensa industrialização, acarretam problemas graves, levando à degradação ou até mesmo em última instância a extinção deste importante recurso, pois, os rios são os principais receptores dos efluentes sanitários e industriais, se tornando um risco para as populações que têm como principal fonte de abastecimento esta água contaminada, ou seja, não dispõem de água tratada. Segundo estudo da ONU (2003), estima-se que cerca de dois milhões de toneladas, entre eles resíduos industriais, agrícolas e sanitários, são lançados sem tratamento diariamente nos corpos hídricos. Essas comunidades ribeirinhas estão susceptíveis a doenças de veiculação hídrica, como a cólera, a disenteria bacilar, a febre tifóide, a diarréia infantil, a leptospirose, a esquistossomose, a hepatite, a malária, a febre amarela, entre outras. De acordo com a OMS (Organização Mundial de Saúde) cerca de $85 \%$ das doenças conhecidas são de veiculação hídrica.

Os problemas de escassez e degradação dos recursos hídricos acarretados pelos fatores citados anteriormente, registrados no último século, demandam uma mudança de comportamento no uso deste recurso diante da possibilidade de uma crise na disponibilidade de água. Para enfrentar esta questão é necessário que se tomem medidas como a conservação dos recursos 
hídricos, racionalização do uso da água, promovendo um melhor aproveitamento, evitando desperdícios.

O manejo sustentável dos recursos hídricos constitui um dos maiores desafios deste século. Inúmeros organismos mundiais e nacionais que cuidam das questões relativas ao meio ambiente, especialmente da água, têm demonstrado uma maior preocupação quanto ao seu uso racional fronte ao aumento desproporcional do consumo registrado nas últimas décadas. Nessa perspectiva, a gestão dos recursos hídricos atravessa dificuldades no que diz respeito à interação entre seus diferentes atores, como salienta Totti (2008):

(...) a gestão da água enfrenta dificuldades para compatibilizar metas, definir abordagens teóricas adequadas e processar conflitos de interesses envolvendo atores com pesos políticos assimétricos. Procurou-se, deste modo, do ponto de vista institucional, responder a esse desafio através da Constituição Federal de 1988 e da chamada "Lei das águas" (Lei 9433 /1997), que propõe para as bacias hidrográficas um sistema de "gestão participativa”, envolvendo atores governamentais dos três níveis de governo, usuários e representantes da sociedade organizada.

Diante deste quadro, se faz necessário uma gestão participativa, integrada e democrática dos órgãos responsáveis pelo manejo dos recursos hídricos, buscando alternativas para o seu melhor uso, já que a água é um bem de uso comum da humanidade.

Com a necessidade dos agentes gestores dos recursos hídricos intervirem de forma pontual sobre os corpos hídricos, o SIG (Sistema de Informações Geográficas) vem como ferramenta técnica na composição de um banco de dados que irá nortear tais decisões. 


\section{O Rio Paraíba do Sul}

O Rio Paraíba do Sul tem sua nascente no Estado de São Paulo localizado nas coordenadas $\left(23^{\circ} 22^{\prime} \mathrm{S} / 45^{\circ} 52^{\prime} \mathrm{W}\right)$, e deságua no norte fluminense, no município de São João da Barra localizado nas coordenadas $\left(21^{\circ} 37^{\prime} \mathrm{S} / 41^{\circ} 00^{\prime} \mathrm{W}\right)$, percorrendo uma extensão aproximada de $1.150 \mathrm{~km}$. A Bacia do Rio Paraíba do Sul está situada na região Sudeste do Brasil e ocupa aproximadamente $55.400 \mathrm{~km}^{2}$, compreendendo os estados de São Paulo $\left(13.500 \mathrm{~km}^{2}\right)$, Rio de Janeiro $\left(21.000 \mathrm{~km}^{2}\right)$ e Minas Gerais $\left(20.900 \mathrm{~km}^{2}\right)$, abrangendo 180 municípios.

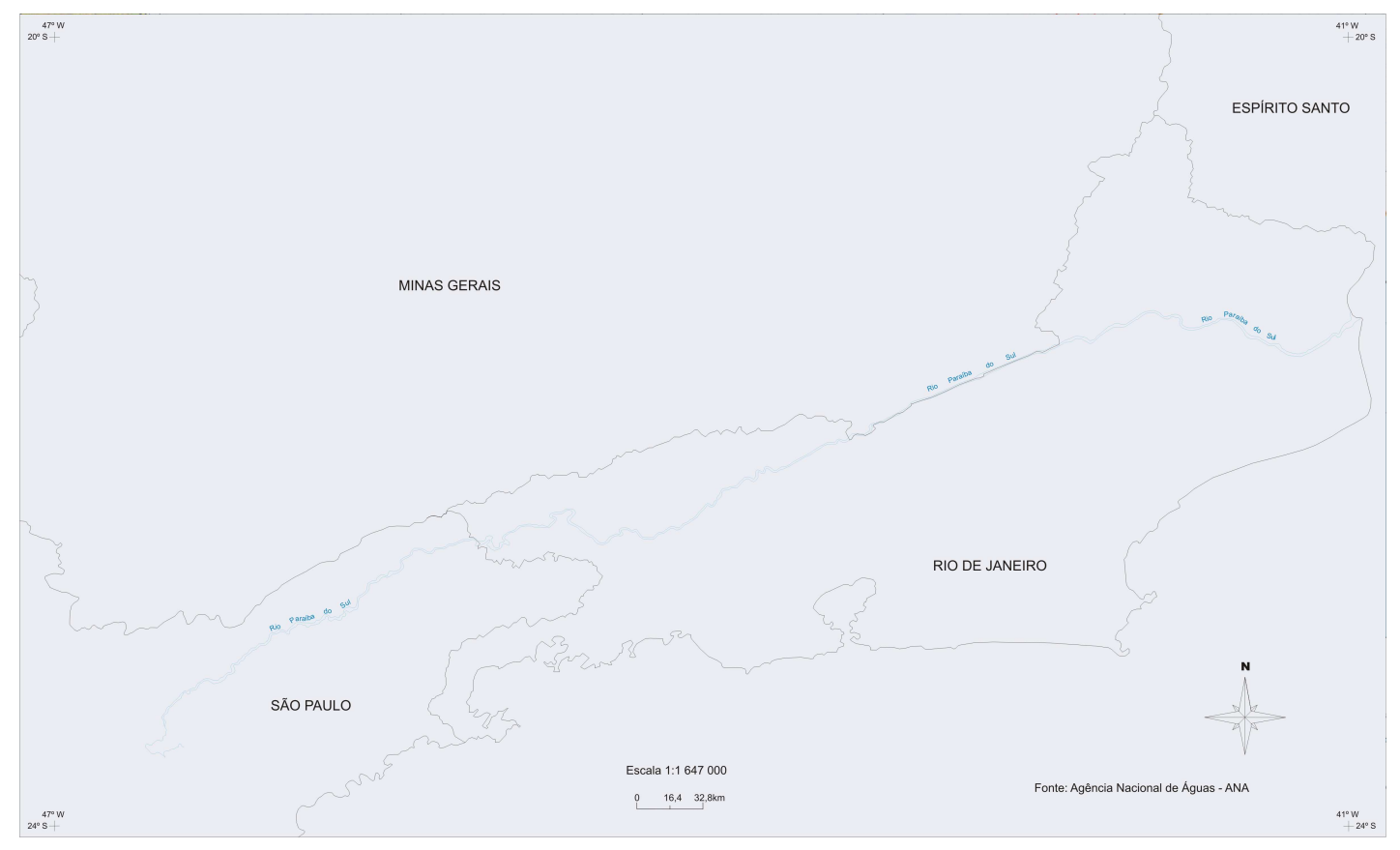

Figura 1: Localização do Rio Paraíba do Sul.

No contexto do Estado do Rio de Janeiro, o Rio Paraíba do Sul possui uma grande importância, já que suas águas abastecem cerca de $80 \%$ da população da capital, assim como de inúmeras cidades da Região Metropolitana, como salienta Portugal (1996):

O grau de importância e de dependência que o Estado do Rio de Janeiro e a Região Metropolitana da cidade do Rio de Janeiro têm em relação à Bacia hidrográfica do Rio Paraíba do Sul é bem maior que se possa, a princípio, imaginar. Para que se tenha uma idéia, esse Rio representa o maior recurso hídrico do Estado e abastece de água potável cerca de 10 milhões de pessoas, $80 \%$ da população da capital e das cidades da Região Metropolitana do Rio de Janeiro.

O Rio Paraíba do Sul não tem recebido a sua devida atenção pelos organismos públicos apesar de ser de suma importância para as localidades que o envolvem. Com isso, encontra-se em estágio avançado de assoreamento e poluição, e pouco se tem feito para evitar tais catástrofes ambientais, ainda que esta problemática venha sendo discutida há muitos anos em Fóruns, 
Conferências, Encontros, onde os intelectuais têm a oportunidade de dialogar com o poder público.

\subsection{A gestão das águas no Paraíba do Sul}

A Bacia do Paraíba do Sul abrange uma infinidade de municípios com uma população total de 5.588.237, da qual a maior parte vive nas áreas urbanas, significando um montante de aproximadamente $89 \%$. Mesmo que a região de sua bacia seja extremamente urbanizada e industrializada, o principal usuário da água, quando se fala em volume de captação, é o setor de irrigação com cerca de $50 \mathrm{~m} / \mathrm{s}$; o abastecimento urbano utiliza aproximadamente $16 \mathrm{~m}^{3} / \mathrm{s}$, enquanto o setor industrial utiliza $14 \mathrm{~m}^{3} / \mathrm{s}$, superando o setor da pecuária, cujo consumo se mostra inferior a $4 \mathrm{~m}^{3} / \mathrm{s}$. (GRUBEN et al., 2005).

Nas ultimas décadas houve um grande inchaço urbano, ou seja, a população das cidades aumentou substancialmente, o que demandara maior volume de água para o abastecimento doméstico, em contrapartida o aumento do fornecimento de água não foi proporcional à coleta do esgoto sanitário, o que significou um prejuízo para o Rio Paraíba do Sul, causando uma deterioração da qualidade das águas fornecidas às populações.

\section{O Rio Paraíba do Sul no contexto da IX Região Hidrográfica}

Desde novembro de 2006, o território do Rio de Janeiro, para fins de gestão dos recursos hídricos, encontra-se subdividido em 10 (dez) Regiões Hidrográficas (Rh's), de acordo com afinidades geopolíticas e as bacias que abrangem. Esta medida foi aprovada pelo Conselho Estadual de Recursos Hídricos, através da Resolução/CERHI-RJ N ${ }^{\circ} 18$ (08/11/2006), tem por objetivo facilitar a gestão deste importante recurso natural e otimizar a aplicação dos recursos financeiros arrecadados com a cobrança pelo uso da água em cada região, possibilitando assim minimizar os conflitos e promover a multiplicidade dos usos, a conservação e a recuperação da água, garantindo o uso racional e sustentável dos corpos hídricos. Assim, cabe ao Inea, garantir e fiscalizar a qualidade das águas no Estado. (Inea - 2008) 
No contexto da IX Região Hidrográfica, o Rio Paraíba exerce extrema importância, pois é o principal corpo hídrico, abrangendo grande quantidade de municípios, além de absorver grande volume de água de afluentes como os rios Pomba e Muriaé. O Rio Paraíba do Sul corta toda a IX Região Hidrográfica no sentido W-E (oeste-leste), passando por municípios como: Aperibé, Cambuci, São Fidélis, Cardoso Moreira, Campos dos Goytacazes, São Francisco de Itabapoana e São João da Barra, onde se localiza sua foz, como demonstra a figura 2.

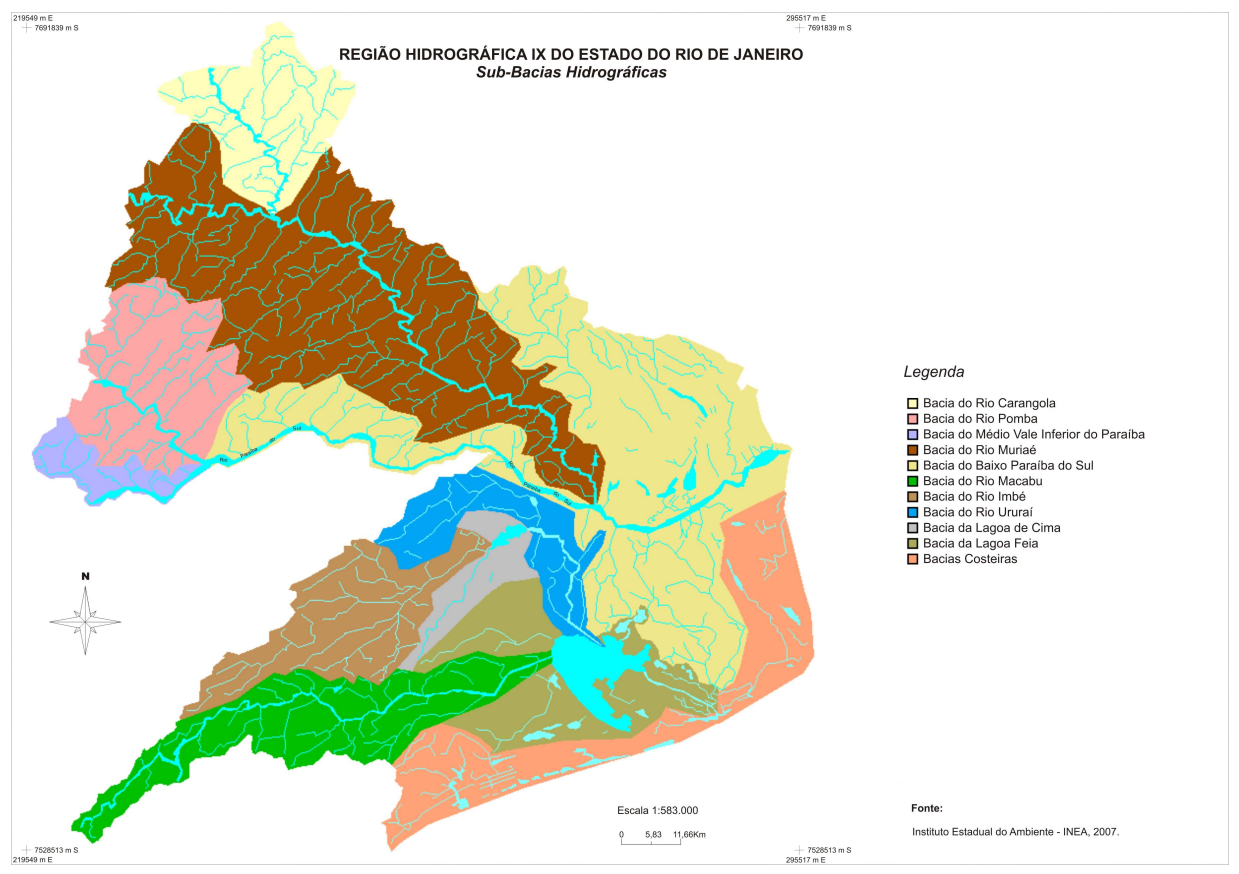

Figura 2: IX Região Hidrográfica do Estado do Rio de Janeiro.

\subsection{Demanda hídrica}

A exemplo do que ocorre em toda a Bacia Hidrográfica do Paraíba do Sul, na IX Região Hidrográfica do Estado do Rio de Janeiro, as atividades que mais demandam água são a agricultura, agropecuária e a indústria, sendo que a primeira se destaca por ocupar grande parte das terras agricultáveis com a monocultura de cana-de-açúcar principalmente no município de Campos dos Goytacazes. No setor industrial se destacam as atividades petrolíferas, farmacêutica e sucro-alcooleira.

\subsection{Degradação do Paraíba do Sul}

Devido às intensas atividades industriais, agrícolas e da pecuária, o Rio Paraíba do Sul tem recebido grande quantidade de resíduos destes setores, além do esgoto sanitário não tratado. As atividades do setor primário vêm preocupando os intelectuais e pesquisadores, pois estão presentes desde o século XVIII com o início do cultivo da cana-de-açúcar, principalmente na região de Campos dos Goytacazes. É oportuno salientar que a queima da cana-de-açúcar empobrece o solo, poluindo-o e deixando resíduos que serão transportados pela ação da chuva e terão como destino final os corpos hídricos, entre eles o Paraíba.

Devido a grande extensão do Rio Paraíba do Sul e por passar por várias regiões, a IX Região Hidrográfica se configura como destino final de todo o impacto ambiental anteriormente causado, 
como ocorrido em 2008 no Sul fluminense, no município de Resende, com o derramamento de produtos tóxicos (inseticidas) nesse trecho do Rio Paraíba do Sul, que causou prejuízos ambientais, econômicos e sociais em grande escala, principalmente nos municípios de Campos dos Goytacazes, São João da Barra e São Francisco de Itabapoana, onde a atividade da pesca é intensa.

Abaixo segue o mapa demonstrativo do lançamento de esgoto doméstico no Paraíba do Sul, medido em DBO (Demanda Bioquímica de Oxigênio).

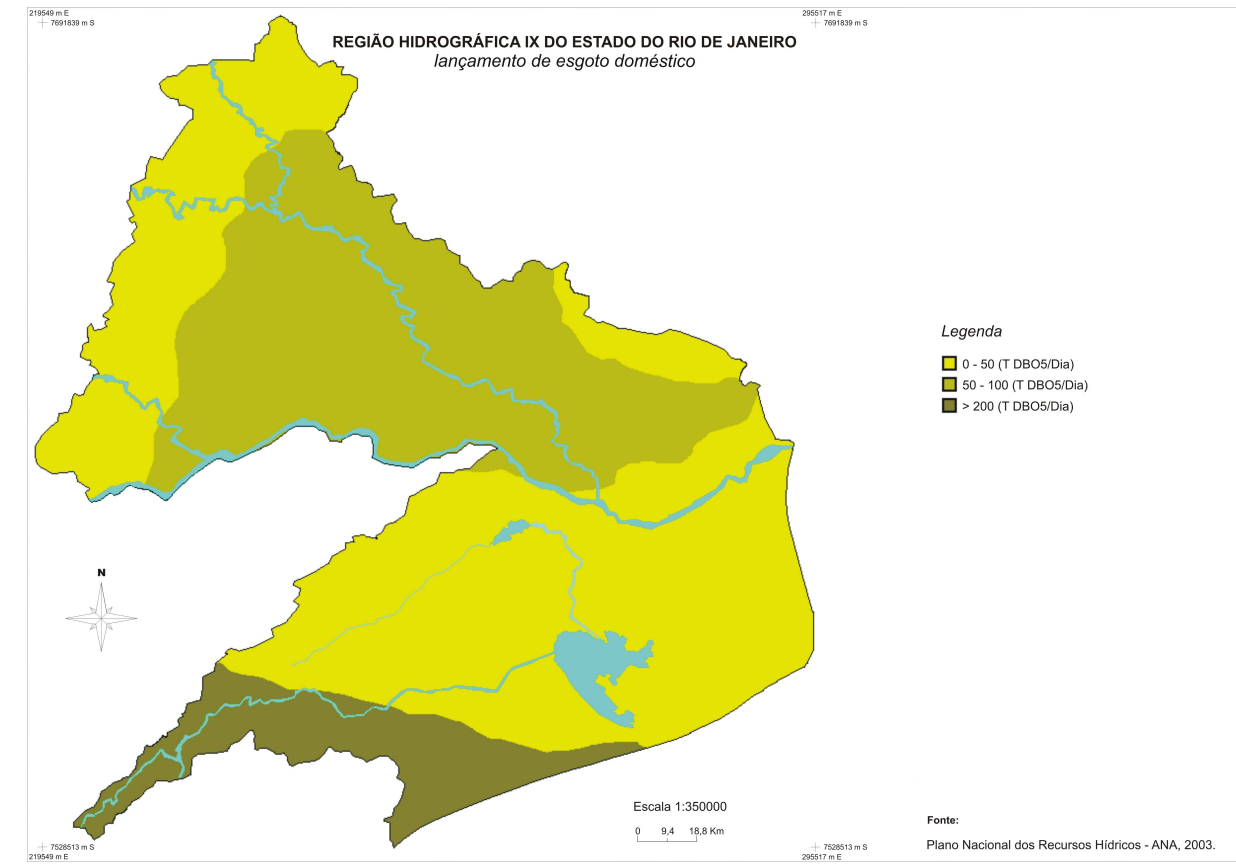

Figura 3: Lançamento de esgotos no Rio Paraíba do Sul.

Com um maior rigor das fiscalizações ambientais, muitas empresas instalaram sistemas de tratamento de efluentes, mas não a ponto suficiente de erradicar o despejo de resíduos nos corpos d'água. O desafio de se enfrentar este problema de frente se dá a medida em que o Governo do Estado não provê os recursos necessários para as obras de saneamento, principalmente no que se refere ao tratamento de esgotos coletados. Algumas cidades têm conseguido encarar este desafio com os recursos oriundos dos royalties do petróleo, a exemplo da prefeitura de Campos dos Goytacazes que tem feito um esforço nessa empreitada. (ENGEVISTA, 2004).

\subsubsection{Degradação no Rio Paraíba do Sul por processos de assoreamento e instabilidade.}

Um outro fator de extrema importância, que merece maior atenção, pois coloca em risco a vida útil do rio é a questão do assoreamento. Esse processo inicia-se com a erosão natural nas encostas, sendo em geral agravados por desmatamentos, abertura de estradas, aterros e exposição de solos, aumentando a carga de sedimentos depositados no fundo do Rio Paraíba do Sul.

Além do assoreamento e sedimentos em suspensão, o Rio Paraíba do Sul está também sujeito a profundas alterações em seu regime hidráulico e na produção de sedimentos, devido à prática de encurtamento do canal pelos cortes de meandros, e aumento da declividade do canal pela intensa atividade de extração de areia em seu leito e várzeas. (ENGEVISTA, 2004). 
Com isso, tais alterações produzem de acordo com a Vale Verde - Associação de Defesa do Meio Ambiente (2004):
(...) instabilidades, cujos efeitos mais imediatos se relacionam com o rebaixamento generalizado das linhas de água ao longo do trecho onde se verifica uma maior extração de areia, diminuindo assim a seção de escoamento, afogamento da descarga dos afluentes, tendo como conseqüencia maiores transbordamentos, e, portanto, maiores e inesperadas enchentes em áreas ribeirinhas.

Diante de tudo que foi dito, fica evidente que o poder publico e os órgãos responsáveis pela gestão das águas necessitam tomar medidas enérgicas e imediatas. Para o auxílio no manejo sustentável dos recursos hídricos no Rio Paraíba do Sul, é de extrema importância a utilização do SIG (Sistema de Informação Geográfica) como ferramenta de manejo deste recurso.

\section{A utilização do SIG como ferramenta de manejo}

A necessidade de integrar vários formatos de dados em um mesmo ambiente, unindo propriedades espaciais e não espaciais, utilizando o conceito de camadas de informação, foi suprida a partir da conceituação de poderosas ferramentas computacionais. Tais ferramentas, que visam a coleta, o armazenamento, a recuperação, a transformação, a análise e a apresentação de dados e informações, espacialmente referenciados, foram sumarizadas no que se convencionou denominar SIG. (SILVA, 2006).

Os SIG's podem ser definidos segundo Aronoff (1989) como:

(...) sistemas automatizados usados para armazenar, analisar $e$ manipular dados geográficos, ou seja, dados que representam objetos e fenômenos em que a localização geográfica é uma característica inerente à informação e indispensável para analisá-la.

O SIG nos possibilita analisar o espaço geográfico e acompanhar o seu dinamismo, através de suas tecnologias, nos permitindo fazer comparações de diferentes tempos históricos e projeções futuras. Segundo Mota (1999):

Os SIGs são utilizados como ferramenta de análise espacial, na modelagem e simulação de cenários, como subsídio à elaboração de alternativas para a decisão da política de uso e ocupação do solo, ordenamento territorial, equipamentos urbanos e monitoramento ambiental, entre outras aplicações complexas, que envolvem diferentes componentes dinâmicos.

Possuindo as características acima enumeradas, o SIG surge como alternativa para a gestão da Bacia do Paraíba do Sul, para tanto há necessidade de se compor um banco de dados georreferenciado, que possibilitará uma atuação mais eficaz e precisa dos órgãos gestores. Segundo Silva (2004):

os referidos sistemas constituem o ambiente de inteligência que dá suporte de forma lógica e estruturante à gestão e ao processo decisório das diferentes esferas de aplicação, permitindo, inclusive, a construção de indicadores, baseados em análises geográficas. 
Faz-se importante destacar a facilidade de integração dos dados das mais diversas áreas, como geologia, geomorfologia, pedologia, demografia, movimentos sociais, urbanismo, saneamento, ecologia entre outras, possibilitando uma abordagem ampla e completa. Portanto, a utilização destes recursos tecnológicos é proposta como instrumento articulador do processo de integração entre o planejamento ambiental e a gestão dos recursos hídricos.

\section{Referência:}

ARONOFF, S. Geographic Information Systems. Ohawa: WDL Publications, 1989.

GRUBEN, Anna; LOPES, P. Duarte; FORMIGA-JOHNSSON, R. Maria, Projeto Marca D’ Água. Bacia13 - Bacia do Paraíba do Sul. São Paulo, Rio de Janeiro e Minas Gerais, 2005.

InStituto ESTAduAl DO AMBIENTE (INEA). Gestão das Águas e do Território, 2009. Disponível em http://www.inea.rj.gov.br/recursos/re_hidrograf.asp, acesso em: 01, out. 2009.

JUNIOR, D. S. A. Degradação da Bacia do Rio Paraíba do Sul. ENGEVISTA, v. 6, n. 3, p. 99-105, 2004

PORTUGAL, Gil. Rio Paraíba do Sul ou Baía da Guanabara?, 1996. Disponível em http://www.gpca.com.br/Gil/art105.htm, acesso em: 01, out. 2009.

SILVA, José Augusto da. Gestão de recursos hídricos e sistemas de informações geográficas: contribuições para a organização sócio-espacial do Pontal do Paranapanema-SP. Presidente Prudente - SP, 2006. 217p. Tese (Doutorado) - Faculdade de Ciências e Tecnologia, Universidade Estadual Paulista.

SILVA, José Augusto da. Recursos de apoio didático-pedagógico na educação ambiental. Presidente Prudente SP, 2001. 252p. Dissertação (Mestrado) - Faculdade de Ciências e Tecnologia, Universidade Estadual Paulista.

TOTTI, M.E.F. Gestão das Águas na Bacia Hidrográfica do Rio Paraíba do Sul: Governança, Instituição e Atores. 2008. p. 133. Tese (Doutorado em Ecologia e Recursos Naturais) - Universidade Estadual do Norte Fluminense - UENF, 2008.

VERDE,Vale, Associação de Defesa do Meio Ambiente. Rio Paraíba do Sul. Dados fornecidos pelo Comitê de Bacias Hidrográficas - Rio Paraíba do Sul e Serra da Mantiqueira, 2004. disponível em http://www.valeverde.org.br/html/ rio2.php\#a19, acesso em: 01, out. 2009. 